\title{
Videography Modelling of the Wave-structure Interaction Processes through Cluster Analysis
}

\author{
Sara Mizar FORMENTIN ${ }^{\bowtie}$, Maria Gabriella GAETA, Giuseppina PALMA, \\ Massimo GUERRERO, Roberto DE VECCHIS and Barbara ZANUTTIGH \\ DICAM, University of Bologna, Italy \\ $\bowtie$ saramizar.formentin2@unibo.it
}

\begin{abstract}
This contribution presents the application of the videography as a low-cost, non-intrusive alternative to measure the wave-structure interaction processes. To this purpose, a full-HD camera was used to film laboratory tests of wave overtopping against a sea-dike. From the image processing, the flow depths over the dikes, the wave celerities, the wave spectra and the amount of the air entrapped in the overtopping tongue were estimated. The results of this analysis were successfully compared to the measurements from traditional techniques.
\end{abstract}

Keywords: videography, cluster analysis, wave-structure interaction, wave overtopping, air entrainment.

\section{INTRODUCTION}

The modelling of the interaction processes between waves and coastal structures is a key-element for the assessment of the safety of the coastland areas. Despite simultaneous measurements of the parameters involved in the interaction processes (run-up, overtopping, reflection, loads, etc. induced by waves) would be essential for an integrated analysis, the use of numerous techniques during the same campaign (resistant gauges, velocimeters, water volume trapping in tanks, pressure sensors) is unaffordable for economic and practical reasons and, especially at small scales of laboratory tests, not recommendable due to the their disturbance of the investigated processes (Soares-Frazão et al. 2009). The videography has been already demonstrated to be a reliable alternative to the traditional techniques in the coastal engineering (i.a., Den Bieman et al. 2020). Following these examples, this paper investigates the effectiveness of the 
videography as a low-cost and non-intrusive tool to model the wave-structure interaction processes during laboratory tests of wave overtopping at sea-dikes (Formentin et al. 2019).

\section{METHODOLOGY}

To the authors' purpose, a full-HD camera was installed in correspondence of the dike crest to film the wave run-up and overtopping processes with an acquisition frequency of $30 \mathrm{~Hz}$. The records were elaborated with the image processing technique developed by Gaeta et al. (2020) based on the clusters analysis (K-means method). Pre- and post-processing filtering techniques were implemented to ease the clustering phase and to achieve a more realistic recognition of the patterns. An example of the cluster mapping is shown in Fig. 1. Here, the magenta and white colours are associated to the "classes" 3 and 5, which can be used to, respectively, track the free surface and estimate the aerated portion of the water body. The association class-object relies on human supervision in a training phase of the technique. The trained method (i.e., the classobject association) remains valid for unchanged light condition during following phases.
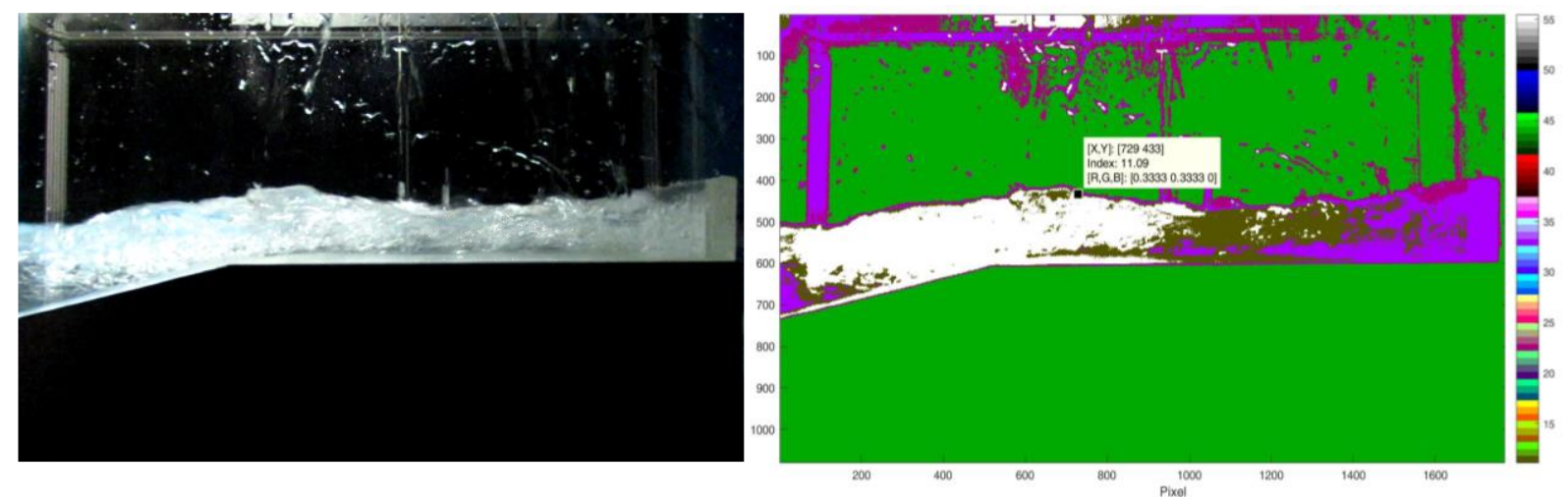

Fig. 1. Wave overtopping event at the dike (left) and corresponding clusters mapping (right).

\section{PRELIMINARY RESULTS}

The results of the image processing were elaborated to reconstruct the overtopping flow depths, the water front celerities and the wave spectra and to get an estimation of the amount of the air entrainment associated to the overtopping events. Comparisons with laboratory measurements of the overtopping flow characteristics derived from gauges (water levels, spectra) and ultra-

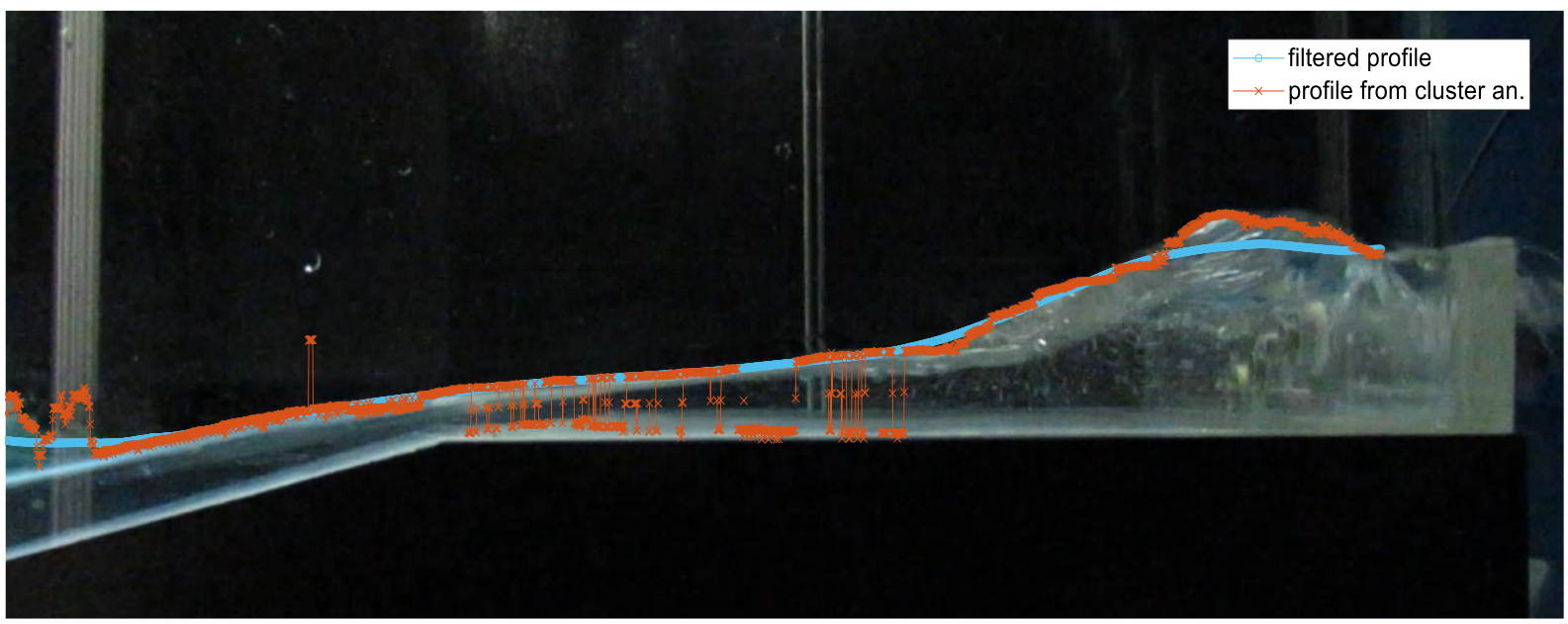

Fig. 2. Reconstruction of the free surface from the cluster analysis of an overtopping event at the dike. 
sonic Doppler velocimeters (depths, velocities, and air amount) are carried out and discussed. Figure 2 shows the water surface elevation resulted from the cluster analysis (orange) and optimized with the filtering techniques (cyan) during an overtopping event.

\section{References}

Den Bieman, J.P., M.P. de Ridder, and M.R.A. van Gent (2020), Deep learning video analysis as measurement technique in physical models, Coastal Eng. 158, 103689, DOI: 10.1016/j.coastaleng. 2020.103689.

Formentin, S.M., M.G. Gaeta, G. Palma, B. Zanuttigh, and M. Guerrero (2019), Flow depths and velocities across a smooth dike crest, Water 11, 10, 2197, DOI: 10.3390/w11102197.

Gaeta, M.G., M. Guerrero, S.M. Formentin, G. Palma, and B. Zanuttigh (2020), Non-intrusive measurements of wave-induced flow over dikes by means of a combined ultrasound Doppler velocimetry and videography, Water 12, 11, 3053; DOI: 10.3390/w12113053.

Soares-Frazão, S., Y. Zech, and F. Alcrudo (2009), Laboratory experiments. In: D. de Wrachien and S. Mambretti (eds.), Dam-break Problems, Solutions, and Case Studies, Ch. 2, 51-84, WIT Press, Ashurst Lodge, UK. 